\title{
Совершенствование
} противопожарного обустройства лесов Российской Федерации

\author{
(C) Ю.3. Шур, А.А. Степченко, Е.Н. Горовая, Н.В. Шаповал,
} И.С. Шепелёва

\section{Improving of Russian Federation forests fire prevention}

Y.Z. Shur, A.A. Stepchenko, E.N. Gorovaya, N.V. Shapoval, I.S. Shepelyova (Saint Petersburg Forestry Research Institute)

In this paper a new methodical approach to improving of Russian Federation forests fire prevention is proposed. Russian Federation forest fire prevention lows, instructions and publications have been analyzed. Current forest fire prevention normatives have been explored also. Main flaws of these documents have been identified. Given flaws are connected with wrong forming fire prevention measure list. These measures are concerned other forestry directions. Incorrect forest fire prevention algorithms are the main flaw also. The other flaw is low monitoring opportunities for planned forest fire prevention measures. Forest fire prevention measures list have been corrected. Some forest codex parts should be corrected also. Corrected fire prevention measure list and their units are given. Tables forest fire prevention normatives should be replaced forest fire prevention rules. For example, total amount of fire prevention banners is equally the sum rest zones in the subforestry and total amount road intersection with the subforestry boundary. All forests fire prevention rules are given in this paper.

Key words: forest fire prevention, forest fire prevention rules, forest fire prevention barriers, prescribed burning, recreation zones construction

Совершенствование противопожарного обустройства лесов Российской Федерации Ю.З. Шур, А.А. Степченко, Е.Н. Горовая, Н.В. Шаповал, И.С. Шепелёва

В статье изложен новый методический подход к совершенствованию противопожарного обустройства лесов Российской Федерации. При проведении исследования проанализи- 
рованы нормативно-правовые, инструктивно-методические документы и литературные источники по проблемам противопожарного обустройства лесов Российской Федерации. Были также изучены существующие нормативы противопожарного обустройства лесов и выявлены их основные недостатки. К ним относятся включение в список мер по противопожарному обустройству лесов мероприятий, функционально в первую очередь связанных с другими направлениями лесного хозяйства, недостаточно четкое определение алгоритмов, на основании которых рассчитываются в численном виде нормативы противопожарного обустройства лесов, а также затрудненность мониторинга фактической реализации плановых объемов мероприятий по противопожарному обустройству лесов. Предлагается существенно откорректировать список мер противопожарного обустройства лесов, отраженный в Лесном Кодексе Российской Федерации, отнеся меры, непосредственно не связанные с охраной лесов от пожаров, к другим статьям этого документа, отражающим основное назначение данных мероприятий. Приводится откорректированный список мероприятий, непосредственно связанных с противопожарным обустройством лесов, и их единицы измерения. Предлагается также заменить таблицы с численными значениями нормативов противопожарного обустройства лесов строгими правилами их определения. Так, нормативное число аншлагов предлагается рассчитывать как сумму числа зон отдыха, расположенных на территории участкового лесничества, и числа точек пересечения съездов с дороги общего пользования любой категории с границей участкового лесничества. Совокупность предложенных правил определения нормативов противопожарного обустройства лесов Российской Федерации приводится в данной статье.

Ключевые слова: противопожарное обустройство лесов, правила противопожарного обустройства лесов, противопожарные минерализованные полосы, профилактические контролируемые противопожарные выжигания, благоустройство зон отдыха

Шур Юрий Зиновьевич - канд. экон. наук, начальник научно-исследовательского отдела организации охраны леса от пожаров

E-mail: ffml@spb-niilh.ru

Степченко Александр Анатольевич - канд. геогр. наук, заместитель директора ФБУ «СПбНИИЛХ»

Горовая Елена Наумовна - канд. физ.-мат. наук, ст. науч. сотр. НИО организации охраны леса от пожаров

Шаповал Наталья Валентиновна - инженер-исследователь НИО организации охраны леса от пожаров

Шепелёва Ирина Сёменовна - начальник проектно-технологического сектора НИО организации охраны леса от пожаров

ФБУ «Санкт-Петербургский научно-исследовательский институт лесного хозяйства» 194021, Санкт-Петербург, Институтский пр., 21

Тел.: (812)552-80-21

E-mail: mail@spb-niilh.ru 


\section{Введение}

В соответствии со статьей 53.1 Лесного кодекса Российской Федерации [2] (далее ЛК РФ) предупреждение лесных пожаров предусматривает противопожарное обустройство лесов. Оно представляет собой комплекс мер (мероприятий) по уменьшению вероятности возникновения лесных пожаров и ограничению их распространения.

Противопожарное обустройство лесов базируется на соответствующих нормативах, которые в настоящее время определяются на основании приказа Рослесхоза от 27.04.2012 г. № 174 «Об утверждении Нормативов противопожарного обустройства лесов» [6]. Основными методическими недостатками существующих нормативов являются:

- включение в список мер по противопожарному обустройству лесов мероприятий, функционально в первую очередь связанных с другими направлениями лесного хозяйства, в том числе с мониторингом пожарной опасности в лесах и лесных пожаров, а также с их тушением;

- недостаточно четкое определение алгоритмов (правил), на основании которых нормативы рассчитываются в численном виде;

- затрудненность мониторинга фактической реализации плановых объемов мероприятий.

Учитывая перечисленные выше недостатки, следует сделать вывод о том, что имеется настоятельная необходимость совершенствования противопожарного обустройства лесов.

Результаты исследования и их обсуждение

В результате анализа существующих нормативно-правовых и инструктивно-методических документов предлагается исключить из списка мероприятий по противопожарному обустройству лесов те, что функционально в первую очередь связаны с другими направлениями лесного хозяйства.

Так, «Строительство, реконструкцию и эксплуатацию лесных дорог, предназначенных для охраны лесов от пожаров» следует отнести к мероприятиям лесной инфраструктуры. Это связано с тем, что любая лесная дорога может быть использована в целях охраны лесов от пожаров. Кроме того, в соответствии с распоряжением Правительства Российской Федерации от 17.07.2012 г. № 1283-р «Перечень объектов лесной инфраструктуры для защитных лесов, эксплуатационных лесов и резервных лесов» [11] (далее - распоряжение № 1283-p) лесная дорога относится к объекту лесной инфраструктуры, предназначенному для использования, охраны, защиты и воспроизводства лесов.

В связи с этим необходимо внести изменение в часть 2 статьи 53.1 ЛК РФ, удалив из нее мероприятие «Строительство, реконструкция и эксплуатация лесных дорог, предназначенных для охраны лесов от пожаров», и отразить его в статье 13 ЛК РФ «Лесная инфраструктура».

«Строительство, реконструкцию и эксплуатацию посадочных площадок для самолетов, вертолетов, используемых в целях проведения авиационных работ по охране и защите лесов» предлагается отнести к мероприятиям лесной инфраструктуры, поскольку любая посадочная площадка имеет многофункциональное назначение. Она может быть использована как в целях охраны лесов от пожаров, так и для защиты лесов. В соответствии с распоряжением № 1283-р посадочная площадка для самолетов, вертолетов, используемых в целях проведения авиационных работ по охране и защите лесов, относится к объекту лесной инфраструктуры для защитных, эксплуатационных и резервных лесов.

«Проведение работ по гидромелиорации» предлагается исключить из списка мероприятий по противопожарному обустройству лесов. Гидромелиорация - это улучшение гидрологического режима экосистем путем орошения или осушения. Гидролесомелиорация, в свою очередь, система мероприятий по регулированию водного режима земель лесного фонда, направленная на улучшение их использования, то есть на получение дополни- 
тельного прироста древесины, улучшение качества посадочного материала, выращиваемого в питомниках, рост урожайности плодовых и ягодных культур [14]. Таким образом, проведение работ по гидромелиорации в первую очередь относится к лесоведению и лесоводству, и в ряде случаев дает противопожарный эффект, но не направлено напрямую на предупреждение лесных пожаров. Данного рода мероприятие должно быть приведено в главе 4 ЛК РФ «Воспроизводство лесов и лесоразведение», определяющей мероприятия по лесоведению и лесоводству, а не в статье 53.1 ЛК РФ «Предупреждение лесных пожаров».

«Прокладку просек» и «Прочистку просек и их обновление» предлагается отнести к мероприятиям лесной инфраструктуры. Это определяется тем, что основное функциональное назначение просек не связано с предупреждением лесных пожаров. В связи с этим необходимо внести изменения в часть 2 статьи 53.1 ЛК РФ, удалив из мероприятия «Прокладка просек, противопожарных разрывов, устройство противопожарных минерализованных полос» часть, касающуюся «Прокладки просек», и в постановление Правительства Российской Федерации от 16.04.2011 г. № 281 «О мерах противопожарного обустройства лесов» [3] (далее - постановление № 281), удалив из мероприятия «Прочистка просек, прочистка противопожарных минерализованных полос и их обновление» часть, касающуюся «Прочистки и обновления просек». Проведение данных мероприятий необходимо отразить в статье 13 ЛК РФ «Лесная инфраструктура».

«Снижение природной пожарной опасности лесов путем регулирования породного состава лесных насаждений» предлагается исключить из списка мероприятий по противопожарному обустройству лесов. Это связано с тем, что в соответствии с Рекомендациями по противопожарной профилактике в лесах и регламентации работы лесопожарных служб, утвержденными Рослесхозом 17.12.1997 [12], необходимо:
- регулировать состав хвойных древостоев (особенно в молодняках и средневозрастных насаждениях) в порядке рубок ухода за лесом, сохраняя, где это целесообразно, равномерную примесь лиственных пород по всем ярусам в количестве 2-3 единиц;

- вводить в культуры хвойных пород, где это возможно по лесорастительным условиям, примесь деревьев хозяйственно ценных лиственных пород - дуб, клен, ясень, липу, рябину, ольху серую и др.;

- по мере роста культур, в зависимости от степени пожарной опасности участков и хозяйственной целесообразности, деревья лиственных пород в составе хвойных древостоев могут быть сохранены лишь во втором ярусе и подлеске.

Регулирование породного состава лесных насаждений связано с уходом за лесами, который в редакции части 1 статьи 64 ЛК РФ «... представляет собой осуществление мероприятий, направленных на повышение продуктивности лесов, сохранение их полезных функций (рубка части деревьев, кустарников, агролесомелиоративные и иные мероприятия)».

В соответствии с приказом Минприроды России от 22 ноября 2017 г. № 626 «Об утверждении Правил ухода за лесами» [9] (далее Правила ухода за лесами), одним из мероприятий по уходу за лесами являются рубки ухода.

Таким образом, из упомянутых выше документов следует, что противопожарный эффект рубок ухода является частным (второстепенным) эффектом и не имеет прямого отношения к мероприятиям по противопожарному обустройству лесов.

Помимо этого, ряд мероприятий надо исключить из списка мер противопожарного обустройства лесов в связи с тем, что их основное функциональное назначение связано с мониторингом пожарной опасности в лесах и лесных пожаров, а также их тушением.

«Строительство, реконструкцию и эксплуатацию пожарных наблюдательных пунктов (вышек, мачт, павильонов и других на- 
блюдательных пунктов)» предлагается отнести к мероприятию «Организации системы обнаружения лесных пожаров». Это связано с тем, что в соответствии с пунктом 2 части 1 статьи 53.2 ЛК РФ одним из мероприятий по мониторингу пожарной опасности в лесах и лесных пожаров является организация системы обнаружения лесных пожаров.

«Строительство, реконструкцию и эксплуатацию пунктов сосредоточения противопожарного инвентаря» предлагается перенести в список мероприятий по тушению лесных пожаров (статья 53.4 ЛК РФ). При этом часть 1 статьи 53.4 ЛК РФ необходимо дополнить группой мероприятий по тушению лесных пожаров «Организационно-технических мероприятий по тушению лесных пожаров» (ввести пункт 7), куда и занести данное мероприятие.

В связи с вышеизложенным, необходимо внести изменение в часть 2 статьи 53.1 ЛК РФ, удалив из нее мероприятие «Строительство, реконструкция и эксплуатация пожарных наблюдательных пунктов (вышек, мачт, павильонов и других наблюдательных пунктов), пунктов сосредоточения противопожарного инвентаря».

«Устройство пожарных водоемов и подъездов к источникам противопожарного водоснабжения» предлагается перенести в список мероприятий по тушению лесных пожаров (статья 53.4 ЛК РФ, группа мероприятий «Организационно-технические мероприятия по тушению лесных пожаров»).

«Создание и содержание противопожарных заслонов» предлагается исключить из списка мероприятий по противопожарному обустройству лесов. Это связано с тем, что противопожарный заслон - это полоса леса шириной от 30 до 320 м, расположенная на границе земель лесного фонда с землями иных категорий и обладающая следующими характеристиками: лесные, покрытые лесом земли с группой пород первого яруса - хвойные с полнотой меньше 0,7 , с отсутствием второго яруса из хвойных, с отсутствием гу- стого и высокого хвойного подроста и густого хвойного подлеска. Как известно, основное назначение противопожарных заслонов состоит в том, чтобы уменьшать вероятность возникновения верховых лесных пожаров, то есть перехода низовых в верховые. Вероятность возникновения верховых пожаров высока в тех лесотаксационных выделах, где имеются следующие лесорастительные условия: лесная, покрытая лесной растительностью площадь, группа преобладающих пород первого яруса - хвойные с полнотой больше 0,7 , имеется второй ярус из хвойных, густой и высокий хвойный подрост и густой хвойный подлесок.

Рассмотрим ситуацию, когда верховой пожар возник на землях лесного фонда и движется в направлении земель иных категорий. Вероятность того, что он возник и развивается в полосе земель лесного фонда шириной от 30 до 320 м, непосредственно примыкающей к землям иных категорий, крайне мала. В таком случае противопожарный заслон не сможет остановить уже развивающийся верховой лесной пожар.

Рассмотрим другую ситуацию, когда пожар возник на землях иных категорий и распространяется в направлении земель лесного фонда. В этом случае нераспространение пожара на земли лесного фонда должно быть обеспечено мерами пожарной безопасности, осуществляемыми на землях иных категорий, которые соответствующим образом регламентируются.

Проанализируем данную проблему с иной стороны, а именно, с точки зрения ее правового обоснования. Как отмечалось выше, для снижения вероятности возникновения верховых лесных пожаров нужно снизить густоту хвойного подлеска и подроста. Это можно осуществить путем соответствующих рубок ухода. Естественно, что в результате проведения данных рубок может быть достигнут и противопожарный эффект. Следует также подчеркнуть, что в качестве единственного непосредственно противопожарного мероприятия в Правилах 
ухода за лесами упоминается следующее: «... в опушках хвойных и твердолиственных лесных насаждений вдоль железных и автомобильных дорог, а также в опушках, примыкающих к сельскохозяйственным угодьям, в противопожарных целях должно производиться удаление на деревьях с низко опущенными кронами нижних сухих ветвей».

Формулировку «Благоустройство зон от- дыха граждан, пребывающих в лесах в соответствии со статьей 11 Лесного кодекса Российской Федерации» в постановлении № 281 предлагается заменить на «Благоустройство зон отдыха граждан, пребывающих в лесах» в связи с избыточностью первой.

Откорректированный список мероприятий по противопожарному обустройству лесов и их единиц измерения приведен в таблице.

Таблица

Откорректированный список мероприятий по противопожарному обустройству лесов

Мероприятие по противопожарному обустройству лесов

Единица измерения

\begin{tabular}{|c|c|}
\hline $\begin{array}{l}\text { Установка и размещение стендов и других знаков и указателей, содержащих } \\
\text { информацию о мерах пожарной безопасности в лесах, в виде: }\end{array}$ & Шт. \\
\hline стендов & шт. \\
\hline объявлений (аншлагов) & Шт. \\
\hline Благоустройство зон отдыха граждан, пребывающих в лесах: & Шт. \\
\hline создание зон отдыха & Шт. \\
\hline эксплуатация зон отдыха & Шт. \\
\hline $\begin{array}{l}\text { Установка и эксплуатация шлагбаумов, устройство преград, обеспечивающих } \\
\text { ограничение пребывания граждан в лесах в целях обеспечения пожарной } \\
\text { безопасности: }\end{array}$ & шт. \\
\hline установка шлагбаумов & Шт. \\
\hline эксплуатация шлагбаумов & шт. \\
\hline устройство преград & шт. \\
\hline $\begin{array}{l}\text { Прокладка противопожарных разрывов, устройство противопожарных мине- } \\
\text { рализованных полос: }\end{array}$ & KM \\
\hline прокладка противопожарных разрывов & KM \\
\hline устройство противопожарных минерализованных полос & KM \\
\hline Прочистка противопожарных минерализованных полос и их обновление & KM \\
\hline $\begin{array}{l}\text { Проведение профилактического контролируемого противопожарного вы- } \\
\text { жигания хвороста, лесной подстилки, сухой травы и других лесных горючих } \\
\text { материалов }\end{array}$ & га \\
\hline Устройство лиственных опушек & KM \\
\hline
\end{tabular}

Как отмечалось выше, другими недостатками существующей системы нормативов противопожарного обустройства лесов являются:

- недостаточно четкое определение алгоритмов (правил), на основании которых рассчитываются в численном виде нормативы противопожарного обустройства лесов;

- затрудненность мониторинга фактической реализации плановых объемов мероприятий по противопожарному обустройству лесов.

Для их устранения логично ввести правила противопожарного обустройства лесов на 
землях лесного фонда. Что касается земель иных категорий, то меры пожарной безопасности для них определяются утвержденными постановлением Правительства РФ от 30.06.2007 г. № 417 Правилами пожарной безопасности в лесах [8], постановлением Правительства РФ от 25.04.2012 г. № $390 « \mathrm{O}$ противопожарном режиме» [4] и рядом других нормативных документов.

В предлагаемых Правилах противопожарного обустройства лесов будут использоваться следующие термины и определения.

Благоустройство зон отдыха - создание и эксплуатация зон отдыха.

Зона отдыха - элемент благоустройства лесов на территории, прилегающей к рекреационным объектам, в целях снижения неблагоприятного воздействия на естественную природную среду.

Лесокультурный разрыв - это полоса земной поверхности шириной 4-6 м между двумя блоками лесных культур, свободная от древесных насаждений, с противопожарной минерализованной полосой посередине.

Лиственная опушка - полоса леса шириной от 150 до 300 м, расположенная на лесных, покрытых лесом землях лесного фонда, примыкающая к землям иных категорий и обладающая следующими характеристиками: лесные, покрытые лесом земли с долей лиственных пород в первом ярусе не менее 0,7 .

Опушка - полоса леса шириной от 150 до 300 м, расположенная на лесных, покрытых лесом землях лесного фонда, примыкающая к землям иных категорий.

Плановый период - отрезок времени, составляющий 10 лет для неарендуемой территории и период, равный сроку аренды соответствующего лесного участка, но не более чем 10 лет - для арендуемой территории.

Пожароопасный сезон - отрезок времени внутри календарного года, в течение которого возможно возникновение лесных пожаров.

Противопожарная минерализованная полоса - это полоса поверхности земли определенной ширины, очищенная от лесных горю- чих материалов или обработанная почвообрабатывающими орудиями либо иным способом до сплошного минерального слоя почвы.

Профилактическое контролируемое противопожарное выжигание - это выжигание лесного напочвенного покрова и лесной подстилки, осуществляемое в результате искусственного инициирования процесса их горения.

Рекреационная нагрузка - степень непосредственного влияния пребывающих в лесах граждан (туристов, рыболовов, охотников и др.), их транспортных средств и т. п. на рекреационные объекты. Выражается числом человеко-дней на единицу площади или рекреационный объект и сопоставляется с рекреационной емкостью объекта. Рекреационная емкость - максимально допустимое количество пребывающих в лесах граждан, которые могут одновременно отдыхать на определенном природном участке.

Рекреационный объект - используемый для отдыха природный участок (озеро, пруд, лесная поляна, видовая площадка и т. п.) [1].

Эксплуатация - комплекс мероприятий по содержанию, обслуживанию и ремонту зданий, сооружений, объектов инфраструктуры и т. п.

Элемент зоны отдыха - одна из малых архитектурных форм, в том числе с прилегающей территорией. Малые архитектурные формы - сооружения, предназначенные для архитектурно-планировочной организации объектов ландшафтной архитектуры, создания условий для комфортного отдыха посетителей, ландшафтно-эстетического обогащения территории в целом (беседка, стол, скамейка и т. п.) [13].

Нормативное число стендов по мероприятию «Установка и размещение стендов и других знаков и указателей, содержащих информацию о мерах пожарной безопасности в лесах, в виде стендов» равно числу лесничеств, лесопарков в субъекте Российской Федерации.

Нормативное число аншлагов по мероприятию «Установка и размещение стендов и 
других знаков и указателей, содержащих информацию о мерах пожарной безопасности в лесах, в виде объявлений (аншлагов)» равно сумме числа зон отдыха, расположенных на территории участкового лесничества, и числа точек пересечения съездов с дороги общего пользования любой категории с границей участкового лесничества.

Стенды и аншлаги должны быть установлены до начала пожароопасного сезона.

Нормативное число зон отдыха по мероприятию «Создание зон отдыха граждан, пребывающих в лесах» для участкового лесничества равно общему числу точек с высокой среднегодовой единовременной рекреационной нагрузкой по всем рекреационным объектам, расположенным на территории участкового лесничества.

Среднегодовая единовременная рекреационная нагрузка считается высокой, если она не менее чем на $25 \%$ превышает среднегодовую единовременную рекреационную нагрузку для территории участкового лесничества.

Зоны отдыха должны быть созданы в течение планового периода.

Нормативное число зон отдыха по мероприятию «Эксплуатация зон отдыха граждан, пребывающих в лесах» равно их фактическому числу на начало планового периода и ежегодно корректируется в течение планового периода с учетом вновь созданных зон отдыха за предшествующие годы планового периода.

Предполагается, что хотя бы один из элементов зоны отдыха подлежит ремонту ежегодно.

Нормативное число шлагбаумов по мероприятию «Установка шлагбаумов, обеспечивающих ограничение пребывания граждан в лесах в целях обеспечения пожарной безопасности» для участкового лесничества равно числу точек пересечения съездов с дороги общего пользования любой категории с границей участкового лесничества за вычетом тех съездов, где устроены преграды.

Шлагбаумы должны быть установлены до начала пожароопасного сезона.
Нормативное число шлагбаумов по мероприятию «Эксплуатация шлагбаумов, обеспечивающих ограничение пребывания граждан в лесах в целях обеспечения пожарной безопасности» для участкового лесничества равно их фактическому числу на начало планового периода и ежегодно корректируется в течение планового периода с учетом вновь установленных шлагбаумов за предшествующие годы планового периода.

Нормативное число преград по мероприятию «Устройство преград, обеспечивающих ограничение пребывания граждан в лесах в целях обеспечения пожарной безопасности» для участкового лесничества равно числу точек пересечения съездов с дороги общего пользования любой категории с границей участкового лесничества за вычетом тех съездов, где установлены шлагбаумы. Преграды устраиваются в том случае, если установка шлагбаумов невозможна по тем или иным причинам.

Преграды должны быть установлены до начала пожароопасного сезона.

По мероприятию «Прокладка противопожарных разрывов» рассматриваются только лесокультурные разрывы. Нормативная протяженность противопожарных разрывов по мероприятию «Прокладка противопожарных разрывов» равна суммарной протяженности разрывов, используемых для деления выделов с лесными культурами на блоки, площадь которых соответствует предельной площади лесосек, которая определяется для лесных районов Российской Федерации в соответствии с приложениями 2-35 Правил заготовки древесины и особенностей заготовки древесины в лесничествах, лесопарках, указанных в статье 23 Лесного кодекса Российской Федерации, утвержденных приказом Минприроды России от 13.09.2016 № 474 [7]. Противопожарные разрывы прокладываются по границам двух смежных лесосек. Ширина противопожарных разрывов составляет 4-6 м.

Противопожарные разрывы должны быть проложены до окончания срока закладки лес- 
ных культур на соответствующих выделах.

На лесных участках минерализованные полосы устраиваются для оконтуривания лесных культур. Нормативная протяженность противопожарных минерализованных полос по мероприятию «Устройство противопожарных минерализованных полос» равна суммарному периметру всех лесных участков с лесными культурами.

Устройство противопожарных минерализованных полос осуществляется также по следующим видам мероприятий по противопожарному обустройству лесов:

- прокладка противопожарных разрывов;

- проведение профилактического контролируемого противопожарного выжигания хвороста, лесной подстилки, сухой травы и других лесных горючих материалов;

- устройство лиственных опушек.

Протяженность минерализованных полос, устраиваемых в составе данных мероприятий, не учитывается по мероприятию «Устройство противопожарных минерализованных полос».

Противопожарные минерализованные полосы должны быть устроены до окончания срока закладки лесных культур на соответствующих выделах.

Нормативная протяженность противопожарных минерализованных полос по мероприятию «Прочистка противопожарных минерализованных полос и их обновление» определяется фактической протяженностью противопожарных минерализованных полос, требующих прочистки и обновления, на начало планового периода и ежегодно корректируется с учетом вновь устроенных противопожарных минерализованных полос за предшествующие годы планового периода.

Необходимость прочистки и обновления противопожарных минерализованных полос определяется в соответствии с приказом Рослесхоза от 10.11.2011 г. № 472 «Об утверждении Методических рекомендаций по проведению государственной инвентаризации лесов» [5] (далее - приказ № 472), приложение № 27.
В данном случае не рассматриваются противопожарные минерализованные полосы, которые устраиваются по следующим мероприятиям:

- прокладка противопожарных разрывов;

- проведение профилактического контролируемого противопожарного выжигания хвороста, лесной подстилки, сухой травы и других лесных горючих материалов;

- устройство лиственных опушек.

Прочистка противопожарных минерализованных полос и их обновление в этом случае осуществляется в соответствии с приказом № 472.

Профилактические контролируемые противопожарные выжигания хвороста, лесной подстилки, сухой травы и других лесных горючих материалов проводятся на землях лесного фонда, граничащих с полосами отвода линейных объектов, землями сельскохозяйственного назначения, землями населенных пунктов. Профилактические контролируемые противопожарные выжигания хвороста, лесной подстилки, сухой травы и других лесных горючих материалов проводятся на лесных, непокрытых лесной растительностью, землях лесного фонда, а также на нелесных землях лесного фонда.

Для лесных, не покрытых лесной растительностью, земель лесного фонда, нормативная площадь профилактических контролируемых противопожарных выжиганий по мероприятию «Проведение профилактического контролируемого противопожарного выжигания хвороста, лесной подстилки, сухой травы и других лесных горючих материалов» равна суммарной выжигаемой площади на прогалинах с травяным покровом.

Для нелесных земель лесного фонда нормативная площадь профилактических контролируемых противопожарных выжиганий равна суммарной выжигаемой площади на лугах и полянах, за исключением ландшафтных полян.

Запреты на выжигание сухой травы определяются приказом Рослесхоза от 24.03.1999 г. 
№ 68 «Об утверждении Рекомендаций по созданию защитных противопожарных полос на участках лесного фонда путем контролируемого выжигания сухой травы» [10].

Мероприятие должно быть выполнено до начала пожароопасного сезона.

Устройство лиственных опушек допускается только путем интродукции лиственных пород. Нормативная протяженность лиственных опушек по мероприятию «Устройство лиственных опушек» равна суммарной протяженности опушек с долей лиственных насаждений в составе насаждений первого яруса менее 0,7 , устраиваемых на выделах, граничащих с землями населенных пунктов. Состав насаждений меняется таким образом, чтобы доля лиственных пород в составе насаждений первого яруса стала не менее 0,7 .

Лиственные опушки должны быть устроены в течение планового периода.

\section{Выводы}

В заключение следует отметить, что предлагаемый методический подход по совершенствованию противопожарного обустройства лесов Российской Федерации для своей реализации требует системного изменения лесного законодательства. Однако его внедрение позволит существенно повысить эффективность противопожарного обустройства лесов Российской Федерации.

\section{БИБЛИОГРАФИЧЕСКИЙ СПИСОК}

1. Дедю, И.И. Экологический энциклопедический словарь / И.И. Дедю. - Кишинев: Гл. ред. Молд. сов. энцикл., 1990. - 406 с.

2. Лесной кодекс Российской Федерации: федер. закон от 04.12.2006 г. № 200-ФЗ: ред. от 29.12.2017 г.: принят Гос. Думой 08.11.2006 г.: одобр. Сов. Федер. 24.11.2006 г. // КонсультантПлюс: Офиц. сайт компании «КонсультантПлюс» / Компания «КонсультантПлюс». - Электрон. справ. правовая система. Режим доступа: http://www.consultant.ru/cons/cgi/online.cgi?req=doc\&base=LAW\&n=287077\&r nd=299965.729316262\#0, свободный. - Загл. с экрана. - Яз. рус. - Дата обращения: 18.06.2018.

3. О мерах противопожарного обустройства лесов: Постановление Правительства РФ от 16.04.2011 г. № 281, Москва // КонсультантПлюс: Официальный сайт компании «КонсультантПлюс» / Компания «КонсультантПлюс». - Электрон. справ. правовая система. - Режим доступа: http://www.consultant.ru/ document/cons_doc_LAW_113132/, свободный. - Загл. с экрана. - Яз. рус. - Дата обращения: 18.06.2018.

4. О противопожарном режиме: Постановление Правительства РФ от 25.04.2012 г. № 390 (ред. от 30.12.2017), Москва // КонсультантПлюс: Офиц. сайт компании «КонсультантПлюс» / Компания «КонсультантПлюс». - Электрон. справ. правовая система. - Режим доступа: http://www.consultant. ru/document/cons_doc_LAW_129263, свободный. - Загл. с экрана. - Яз. рус. - Дата обращения: 15.06.2018.

5. Об утверждении Методических рекомендаций по проведению государственной инвентаризации лесов: Приказ Рослесхоза от 10.11.2011 г. № 472 (ред. от 15.03.2018 г.), Москва // КонсультантПлюс: Офиц. сайт компании «КонсультантПлюс» / Компания «КонсультантПлюс». - Электрон. справ. правовая система. - Режим доступа: http://www.consultant.ru/document/cons_doc_LAW_127414/, свободный. - Загл. с экрана. - Яз. рус. - Дата обращения: 22.06.2018.

6. Об утверждении Нормативов противопожарного обустройства лесов: Приказ Рослесхоза от 27.04.2012 г. № 174, Москва: зарегистрирован в Минюсте России 07.06.2012 г. № 24488 // КонсультантПлюс: Официальный сайт компании «КонсультантПлюс» / Компания «КонсультантПлюс». - Электрон. справ. правовая система. - Режим доступа: http://www.consultant.ru/document/cons_doc_LAW_131141/, свободный. - Загл. с экрана. - Яз. рус. - Дата обращения: 20.06.2018. 
7. Об утверждении Правил заготовки древесины и особенностей заготовки древесины в лесничествах, лесопарках, указанных в статье 23 Лесного кодекса Российской Федерации: Приказ Минприроды России от 13.09.2016 № 474 (ред. от 11.01.2017), Москва: зарегистрирован в Минюсте РФ 29.12.2016 № 45041 // КонсультантПлюс: Официальный сайт компании «КонсультантПлюс» / Компания «КонсультантПлюс». - Электрон. справ. правовая система. - Режим доступа: http:/www.consultant.ru/document/ cons_doc_LAW_210680/, свободный. - Загл. с экрана. - Яз. рус. - Дата обращения: 15.06.2018.

8. Об утверждении Правил пожарной безопасности в лесах (с изменениями и дополнениями согласно постановлениям Правительства РФ: от 05.05.2011 г. № 343, от 26.01.2012 г. № 26, от 01.11.2012 г. № 1128, от 14.04.2014 г. № 292, от 18.08.2016 г. № 807): Постановление Правительства РФ от 30.06.2007 г. № 417, Москва // КонсультантПлюс: Официальный сайт компании «КонсультантПлюс» / Компания «КонсультантПлюс». - Электрон. справ. правовая система. - Режим доступа: http://www.consultant.ru/ cons/cgi/online.cgi?req $=$ doc \&base $=$ LAW $\& \mathrm{n}=211360 \& \mathrm{fld}=134 \& \mathrm{dst}=1000000001,0 \& \mathrm{r}$ nd $=0.744631411368289 \# 08823394795589226$, свободный. - Загл. с экрана. - Яз. рус. - Дата обращения: 21.06.2018.

9. Об утверждении Правил ухода за лесами: Приказ Минприроды России от 22.11.2017 г. № 626, Москва: зарегистрирован в Минюсте РФ 22.12.2017 г. № 49381 // КонсультантПлюс: Официальный сайт компании «КонсультантПлюс» / Компания «КонсультантПлюс». - Электрон. справ. правовая система. Режим доступа: http://www.consultant.ru/document/cons_doc_LAW_286334/, свободный. - Загл. с экрана. - Яз. рус. - Дата обращения: 25.06.2018.

10. Об утверждении Рекомендаций по созданию защитных противопожарных полос на участках лесного фонда путем контролируемого выжигания сухой травы: Приказ Рослесхоза от 24.03.1999 г. № 68, Москва // КонсультантПлюс: Офиц. сайт компании «КонсультантПлюс» / Компания «КонсультантПлюс». - Электрон. справ. правовая система. - Режим доступа: http://www.consultant.ru/cons/cgi/online. cgi?req=doc; base=EXP;n=273326\#06030155755327602, свободный. - Загл. с экрана. - Яз. рус. - Дата обращения: 19.06.2018.

11. Перечень объектов лесной инфраструктуры для защитных лесов, эксплуатационных лесов и резервных лесов: утв. Распоряжением Правительства РФ от 17.07.2012 г. № 1283-р (ред. 12.09.2017 г.), Москва // КонсультантПлюс: Официальный сайт компании «КонсультантПлюс» / Компания «КонсультантПлюс». - Электрон. справ. правовая система. - Режим доступа: http:/www.consultant.ru/document/ cons_doc_LAW_132862/, свободный. - Загл. с экрана. - Яз. рус. - Дата обращения: 26.06.2018.

12. Рекомендации по обнаружению и тушению лесных пожаров: утв. Рослесхозом 17.12.1997, Москва // КонсультантПлюс: Официальный сайт компании «КонсультантПлюс» / Компания «КонсультантПлюс». - Электрон. справ. правовая система. - Режим доступа: http://www.consultant.ru/cons/cgi/online. cgi?req=doc;base=EXP; n=269636\#06808451327335099, свободный. - Загл. с экрана. - Яз. рус. - Дата обращения: 26.06.2018.

13. Теодоронский, В.С. Строительство и эксплуатация объектов ландшафтной архитектуры: учебник для студ. высш. учеб. заведений / В.С. Теодоронский, Е.Д. Сабо, В.А. Фролова ; под ред. В.С. Теодоронского. - М.: Издательский центр «Академия», 2006. - 352 с.

14. Энциклопедия лесного хозяйства: в 2-х томах. - Т. 1. - М.: ВНИИЛМ, 2006. / Т.А. Антипенко [и др.]. М.: ВНИИЛМ, 2006. - С. 149. 


\section{REFERENCES}

1. Dedyu I.I. EHkologicheskij ehntsiklopedicheskij slovar’. Kishinev, 1990, p. 406. (In Russian)

2. Lesnoj kodeks Rossijskoj Federacii. 04.12.2006 no. 200-FZ (red. 29.12.2017). Prinyat Gos. Dumoj 08.11.2006, http://www.consultant.ru/cons/cgi/online.cgi? req $=$ doc\&base $=L A W \& n=287077 \& r n d=299965.729316262 \#$. (In Russian)

3. O merakh protivopozharnogo obustrojstva lesov. Postanovlenie Pravitel'stva RF 16.04.2011 no. 281, http:// www.consultant.ru/document/cons_doc_LAW_113132. (In Russian)

4. O protivopozharnom rezhime. Postanovlenie Pravitel'stva RF 25.04.2012 no. 390 (red. 30.12.2017), http://www. consultant.ru/document/cons_doc_LAW_129263. (In Russian)

5. Ob utverzhdenii Metodicheskikh rekomendatsij po provedeniyu gosudarstvennoj inventarizatsii lesov. Prikaz Rosleskhoza 10.11.2011 no. 472 (red. 15.03.2018), http://www.consultant.ru/document/cons_doc_ $L A W_{-}$127414. (In Russian)

6. Ob utverzhdenii Normativov protivopozharnogo obustrojstva lesov. Prikaz Rosleskhoza 27.04.2012 no. 174, http://www.consultant.ru/document/cons_doc_LAW_131141. (In Russian)

7. Ob utverzhdenii Pravil zagotovki drevesiny i osobennostej zagotovki drevesiny v lesnichestvakh, lesoparkakh, ukazannykh v stat'e 23 Lesnogo kodeksa Rossijskoj Federatsii. Prikaz Minprirody Rossii 13.09.2016 no. 474 (red. 11.01.2017), http://www.consultant.ru/document/cons_doc_LAW_210680. (In Russian)

8. Ob utverzhdenii Pravil pozharnoj bezopasnosti v lesakh (s izmeneniyami i dopolneniyami soglasno postanovleniyam Pravitel'stva RF: 05.05.2011 no. 343, 26.01.2012 no. 26, 01.11.2012 no. 1128, 14.04.2014 no. 292, 18.08.2016 no. 807). Postanovlenie Pravitel'stva RF 30.06 .2007 no. 417, http://www.consultant.ru/ cons/cgi/online.cgi $?$ req $=$ doc\&base $=L A W \& n=211360 \& f l d=134 \& d s t=1000000001,0 \& r$ $n d=0.744631411368289 \# 08823394795589226$. (In Russian)

9. Ob utverzhdenii Pravil ukhoda za lesami. Prikaz Minprirody Rossii 22.11.2017 no. 626, http://www.consultant. ru/document/cons_doc_LAW_286334. (In Russian)

10. Ob utverzhdenii Rekomendatsij po sozdaniyu zashhitnykh protivopozharnykh polos na uchastkakh lesnogo fonda putem kontroliruemogo vyzhiganiya sukhoj travy. Prikaz Rosleskhoza 24.03.1999 no. 68, http://www. consultant.ru/cons/cgi/online.cgi? req =doc;base $=E X P ; n=273326 \# 06030155755327602$. (In Russian)

11. Perechen' ob"ektov lesnoj infrastruktury dlya zashhitnykh lesov, ehkspluatatsionnykh lesov i rezervnykh lesov, utv. Rasporyazheniem Pravitel'stva Rossijskoj Federatsii 17.07.2012 no. 1283-r (red. 12.09.2017), http://www. consultant.ru/document/cons_doc_LAW_132862. (In Russian)

12. Rekomendatsii po obnaruzheniyu i tusheniyu lesnykh pozharov, utv. Rosleskhozom 17.12.1997, http://www. consultant.ru/cons/cgi/online.cgi? req $=$ doc $;$ base $=E X P ; n=269636 \# 06808451327335099$. (In Russian)

13. Teodoronskij V.S., Sabo E.D., Frolova V.A. Stroitel'stvo i ehkspluatatsiya ob"ektov landshaftnoj arkhitektury. Moscow, 2006, p. 352. (In Russian)

14. EHnciklopediya lesnogo hozyajstva. Moscow, 2006, pp. 149. (In Russian) 